\title{
Normal reference values of right atrial strain parameters using three-dimensional speckle-tracking echocardiography (results from the MAGYAR-Healthy Study)
}

\author{
Attila Nemes $^{1}$ D $\cdot$ Árpád Kormányos ${ }^{1} \cdot$ Péter Domsik $^{1} \cdot$ Anita Kalapos $^{1} \cdot$ Nóra Ambrus $^{1} \cdot$ Csaba Lengyel $^{2} \cdot$ \\ Tamás Forster ${ }^{1}$
}

Received: 29 May 2019 / Accepted: 19 June 2019 / Published online: 12 July 2019

(c) The Author(s) 2019

\begin{abstract}
Classic echocardiographic methodologies offer limited opportunities in assessing right atrial (RA) morphology and function. Three-dimensional (3D) speckle-tracking echocardiography (3DSTE) is a novel imaging method with objective 3D capability in assessing volumetric and functional properties of heart chambers. Normal reference values of different 3DSTEderived RA strains are not available, therefore the aim of this prospective study was to establish these parameters in healthy subjects. The present study comprised 295 healthy volunteers, from which 110 were excluded due to inadequate image quality. The final population consisted of 185 healthy subjects in the present study (mean age: $32.1 \pm 12.2$ years, 89 males). Complete two-dimensional echocardiography and 3DSTE have been performed in all cases. While radial strain (RS) does not change significantly over the years in males, in female subjects it increases with age most significantly between at the age of 40-49, and it starts to decline at the age of 50 in females. While females have higher circumferential (CS) and area (AS) strain values, CS and AS decrease with age in both gender. While LS remains almost unchanged in females until ages 40-49 years with a decline above the age of 50, it decreases over the decades in males. 3D strain (3DS) increases with age in both gender, but almost doubles in females in older ages. Specific pattern of strains at atrial contraction could also be demonstrated. 3DSTE-derived RA normal reference values with age-, gender-dependency and regional values are demonstrated in a healthy population.
\end{abstract}

Keywords Three-dimensional echocardiography $\cdot$ Right atrium $\cdot$ Strain $\cdot$ Healthy

\section{Introduction}

Right heart failure is a principal cause of morbidity and mortality in different disorders like in pulmonary hypertension [1]. The right atrium (RA) has significant functions during the cardiac cycle: it works as a reservoir in systole, it is a conduit in early diastole and a booster pump in late diastole [2]. Classic echocardiographic methodologies offer limited

Attila Nemes

nemes.attila@med.u-szeged.hu

1 2nd Department of Medicine and Cardiology Centre, Medical Faculty, Albert Szent-Györgyi Clinical Center, University of Szeged, Semmelweis Street 8, P.O. Box 427, Szeged 6725, Hungary

2 1st Department of Medicine, Medical Faculty, Albert Szent-Györgyi Clinical Center, University of Szeged, Szeged, Hungary opportunities in assessing RA morphology and function [2]. Three-dimensional speckle-tracking echocardiography (3DSTE) is a novel imaging method with objective 3D capability in assessing volumetric and functional properties of heart chambers [2, 3]. Strains are objective feature of wall motion and describe wall deformation, which could be calculated from the same 3D model of a particular chamber $[2,3]$. In recent studies, usefulness of 3DSTE in assessing RA uni- and multidirectional strains could be demonstrated [4-7]. With these results, different patterns of RA dysfunction could be suggested in several disorders by 3DSTE [8]. However, normal reference values of different 3DSTEderived RA strains are not available, therefore the aim of this prospective study was to establish these parameters in healthy adult subjects. 


\section{Patients and methods}

\section{Patient population}

The present study comprised 295 healthy volunteers, from which 110 subjects were excluded due to inadequate image quality. The final population consisted of 185 healthy subjects in the present study (mean age: $32.1 \pm 12.2$ years, 89 males). All subjects were taken from the MAGYAR-Healthy Study (Motion Analysis of the heart and Great vessels bY three-dimensionAl speckle-tRacking echocardiography in Healthy subjects), which was organized at our cardiology center to examine normal reference values of 3DSTEderived parameters among others ('magyar' means 'Hungarian' in Hungarian language). Subjects were defined healthy if they had no cardiovascular symptoms without use of any medication, no evidence of any disease, normal result of physical examination and routine two-dimensional Doppler echocardiography. All subjects participated in the study on a voluntary basis. All subjects gave informed consent, the study complied with the Declaration of Helsinki and was approved by the institutional human research committee.

\section{Two-dimensional Doppler echocardiography}

Two-dimensional (2D) Doppler echocardiography was used in all cases to exclude any significant morphological or functional cardiac abnormalities and to assess routine data. Complete transthoracic examination has been performed in all subjects extended with 3DSTE. For 2D Doppler measurements Toshiba Artida ${ }^{\mathrm{TM}}$ echocardiography machine (Toshiba Medical Systems, Tokyo, Japan) was used equipped with a PST-30SBP (1-5 MHz) phased-array transducer. Left atrial and left ventricular (LV) dimensions and LV ejection fraction were assessed according to recent guidelines. Early (E) and late (A) diastolic transmitral flow velocities were measured by pulsed Doppler echocardiography, while valvular regurgitations were excluded by colour Doppler echocardiography.

\section{Three-dimensional speckle-tracking echocardiography}

Apical position was used for data acquisitions with commercially available Toshiba Artida ${ }^{\mathrm{TM}}$ echocardiography equipment with a PST-25SX matrix-array transducer (Toshiba Medical Systems, Tokyo, Japan). During 6 cardiac cycles in sinus rhythm (constant RR interval on ECG) and a single breath-hold, R-wave triggered wedge-shaped subvolumes have been acquired from an apical window to create full-volume 3D echocardiographic datasets for later analysis. Offline analysis was performed from acquired 3D datasets using 3D Wall Motion Tracking software version 2.7 (Toshiba Medical Systems, Tokyo, Japan). Automatic analysis included selection of several views including apical four-chamber (AP4CH) and two-chamber views (AP2CH) of the RA and 3 short-axis views at different (basal, midatrial and superior) RA levels at end-diastole. Following optimizations (gain, magnitude etc.), markers were set by the reader to the edges of the tricuspid annulus (TA) and the endocardial side of the superior RA region (Fig. 1). The endocardial surface of the RA was then automatically reconstructed and a 3D RA cast was performed [2, 4-7].

During volumetric measurements, end-systolic maximum $\mathrm{RA}$ volume $\left(\mathrm{V}_{\max }\right.$, before mitral valve opening), early-diastolic RA volume before atrial contraction $\left(\mathrm{V}_{\mathrm{PreA}}\right.$, at the time of the P-wave on the ECG) and end-diastolic minimum RA volume $\left(\mathrm{V}_{\min }\right.$, before mitral valve closure) were assessed for each subject.

During strain measurements, the following parameters were calculated using the same 3D datasets [2, 4-7]

- Unidirectional strains: radial (RS), longitudinal (LS) and circumferential (CS) and complex strains: area (AS) and 3D (3DS) strains.

- For each strains, global (assessing the whole RA) and mean segmental values (average of strains of the 16 segments) were calculated. Segmental RA strain analysis provided superior, midatrial and basal regional RA strain parameters.

- Peak strain (representing RA reservoir phase) and strain at atrial contraction representing booster pump phase were differentiated.

\section{Statistical analysis}

All continuous variables were presented as mean \pm standard deviation, while categorical data were demonstrated as frequencies and percentages (\%). Comparisons among groups were performed by unpaired Student $t$ test and $\chi^{2}$ test, when appropriate. A 2-tailed $p$ value $<0.05$ was considered to indicate statistical significance. All values were considered significantly different at $\mathrm{p}<0.05$. Statistical analysis was performed by using RStudio (RStudio Team, RStudio: Integrated Development for R. RStudio, Inc., Boston, MA, 2015). For offline data analysis and graph creation, a commercial software package was used (MATLAB 8.6, The MathWorks Inc., Natick, MA, 2015). 

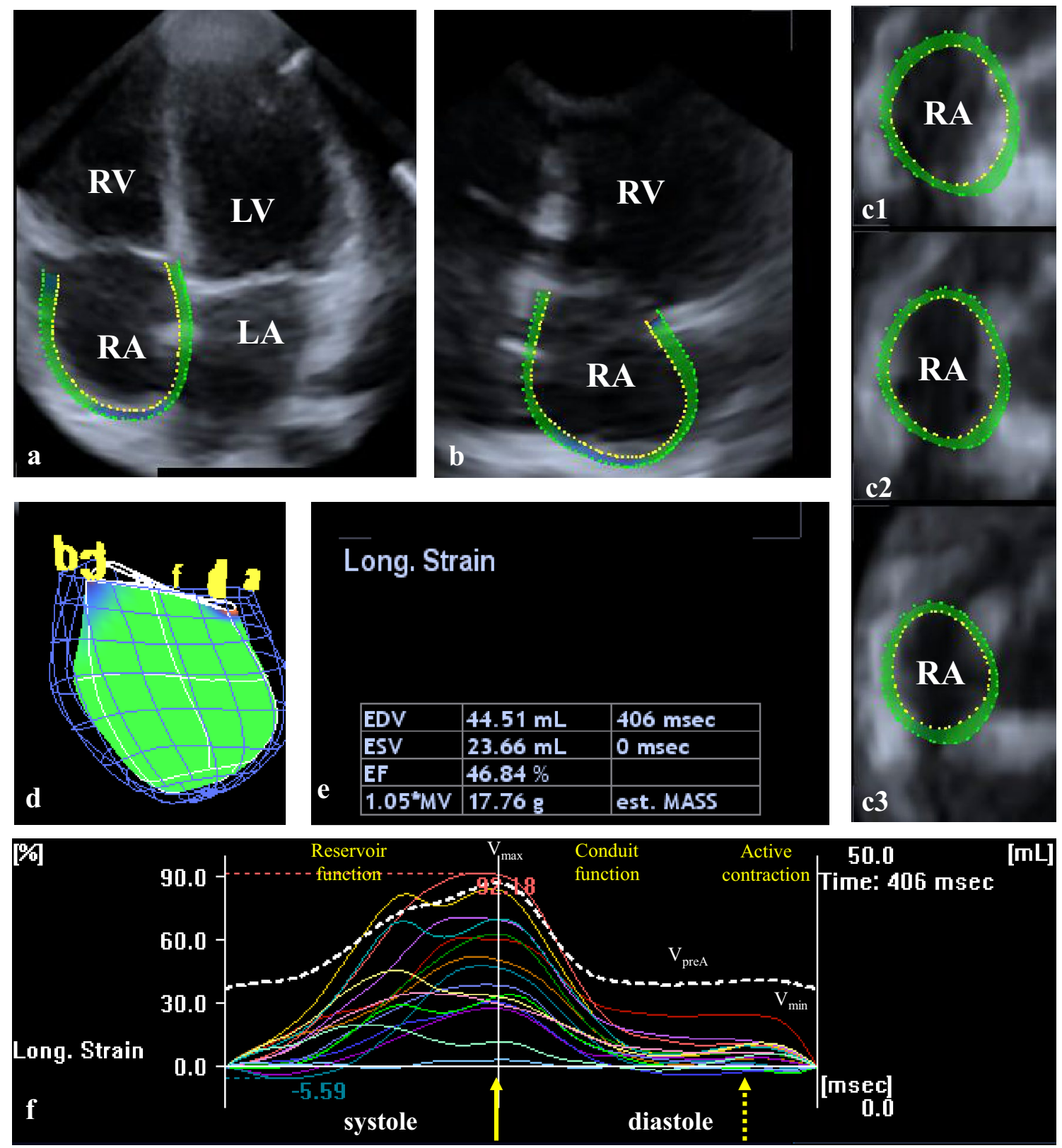

Fig. 1 Images from three-dimensional (3D) full-volume dataset showing the right atrium (RA) in a healthy subject are demonstrated $(\mathbf{a}, \mathbf{b})$ : a apical four-chamber view, b apical two-chamber view, c1 parasternal short-axis view at basal, c2 mid- and c3 superior RA levels. In $\mathbf{d} 3 \mathrm{D}$ reconstruction of the RA based on 3D speckle tracking echocardiographic analysis is presented. In e RA volumetric data are demonstrated. Coloured lines represent segmental RA strains while dashed white line represents RA volume changes over the cardiac cycle (f). Yellow arrow represents peak RA strain, while dashed arrow represents RA strain at atrial contraction. $L A$ left atrium, $L V$ left ventricle, $R A$ right atrium, $R V$ right ventricle

$23.7 \pm 2.8$ years, 59 males $), 30-39$ years $(n=42$; mean age: $33.8 \pm 2.8$ years, 12 males $), 40-49$ years $(n=15$; mean age: $43.9 \pm 3.4$ years, 7 males $)$ and $\geq 50$ years $(n=25$, mean age: $57.3 \pm 5.7$ years, 18 males). Demographic and 2D echocardiographic data were in normal ranges as demonstrated in Table 1.

A total of 185 healthy subjects were included in the study. This group were further divided into the following categories according to their age: $18-29$ years $(n=103$; mean age: 
Table 1 Clinical, two-dimensional and volumetric three-dimensional speckle-tracking echocardiographic data of healthy subjects

\begin{tabular}{ll}
\hline & Data \\
\hline $\mathrm{n}$ & 185 \\
Age (years) & $32.1 \pm 12.2$ \\
Male gender (\%) & $89(48)$ \\
Weight $(\mathrm{kg})$ & $69.5 \pm 14.1$ \\
Height $(\mathrm{cm})$ & $172.2 \pm 9.9$ \\
Body surface area (kg/m $\left.{ }^{2}\right)$ & $1.84 \pm 0.24$ \\
Two-dimensional echocardiography & \\
Left atrium (mm) & $36.5 \pm 3.9$ \\
Left ventricular end-diastolic diameter (mm) & $47.9 \pm 3.7$ \\
Left ventricular end-diastolic volume (ml) & $105.9 \pm 22.9$ \\
Left ventricular end-systolic diameter (mm) & $33.1 \pm 8.7$ \\
Left ventricular end-systolic volume (ml) & $36.3 \pm 9.3$ \\
Interventricular septum (mm) & $8.9 \pm 1.5$ \\
Left ventricular posterior wall (mm) & $9.0 \pm 1.6$ \\
E (cm/s) & $81.4 \pm 17.0$ \\
A (cm/s) & $63.2 \pm 19.0$ \\
Left ventricular ejection fraction $(\%)$ & $65.9 \pm 4.6$ \\
Three-dimensional speckle-tracking echocardiography & \\
Maximum right atrial volume (ml) & $47.3 \pm 14.8$ \\
Preatrial contraction right atrial volume (ml) & $33.9 \pm 11.3$ \\
Minimum right atrial volume (ml) & $26.3 \pm 9.8$ \\
\hline
\end{tabular}

\section{DSTE-derived peak RA strains (reservoir function)}

Peak global RA strains and their gender dependency over decades are demonstrated in Figs. 2 and 4. While RS does not change significantly over the years in males, RS increases with age most significantly between $40-49$ years, and it starts to decline at the age of 50 years in females. While females have higher CS and AS values, these parameters decrease with age in both gender. While LS remains almost unchanged in females until 40-49 years and declines above the age of 50 years in females, it decreases over decades in males. 3DS increases with ages in both gender, but almost doubles in females in older ages. Mean segmental LA strains and differences in regional peak RA strains over decades are demonstrated in Tables 2 and 3.

\section{DSTE-derived RA strains at atrial contraction (booster pump function)}

Peak global RA strains and their gender dependency over decades are demonstrated in Figs. 3 and 4. While RS at atrial contraction does not change over decades in males, an obvious increase could be seen in females with the highest value between $40-49$ years and a decline over 50 years. A decrease could be seen in CS at atrial contraction in males over decades, it is almost tripled in value between
40-49 years in females. Although LS at atrial contraction is higher in females, it decreases over decades in both genders. AS decreases over decades in males, while females have almost doubled AS values at the ages $40-49$ years. 3DS is almost unchanged in males, while doubled but unchanged in older ages in females. Mean segmental LA strains at atrial contraction and differences in regional peak strains over decades are demonstrated in Tables 3 and 4 .

\section{Feasibility of 3DSTE measurements}

During evaluations, 110 subjects were excluded due to inferior image quality from the total of 295 enrolled subjects, therefore the overall feasibility of 3DSTE-derived RA quantification was 185 out of 295 (63\% overall feasibility).

\section{Discussion}

Nowadays, there is an increased attention on the estimation of the right heart due to new opportunities in the treatment of pulmonary circulation. Now there are new possibilities in the non-invasive assessment of RA using recent developments in virtual 3D chamber quantifications during 3DSTE. This imaging methodology is based on a 'block-matching' algorithm for echocardiographic imaging. It allows creation of 3D virtual models of certain heart chambers within a relatively short time. By using this 3D cast of atria and ventricles, not only volumetric but also functional parameters can be assessed at the same time [2-7]. RA has a complex function during cardiac cycle including systolic reservoir, earlydiastolic conduit and late-diastolic booster pump (active contraction) phasic functions [2]. Functional assessment of the RA involves measurement of volume-based functional parameters and strains respecting the cardiac cycle [2, 3]. Twin-peak time-global/segmental strain curves could be created using the 3D cast featuring RA reservoir (first peak) and RA active contraction (second peak) phases.

RA dysfunction by strain assessments could be demonstrated in several disorders including pulmonary hypertension [9], coronary artery disease [10], heart failure [11], etc. or in top-level athletes [12]. 3DSTE-derived RA strains and their specific patterns [8] could be seen in specific disorders like in corrected tetralogy of Fallot [4], noncompaction cardiomyopathy [5], idiopathic hypereosinophilic syndrome [6] and cardiac amyloidosis [7]. Reference values of RA-LS imaging by 2DSTE were also demonstrated [13]. Moreover, tissue velocity imaging (TVI) and strain rate imaging (SRI) were used to determine normal values in the RA (and LA) in normal subjects. Peak systolic and diastolic velocities of the RA (and LA) decreased from the base to the mid and to the roof, while systolic and diastolic strains and strain rates increased from the base to the mid to the roof [14]. 


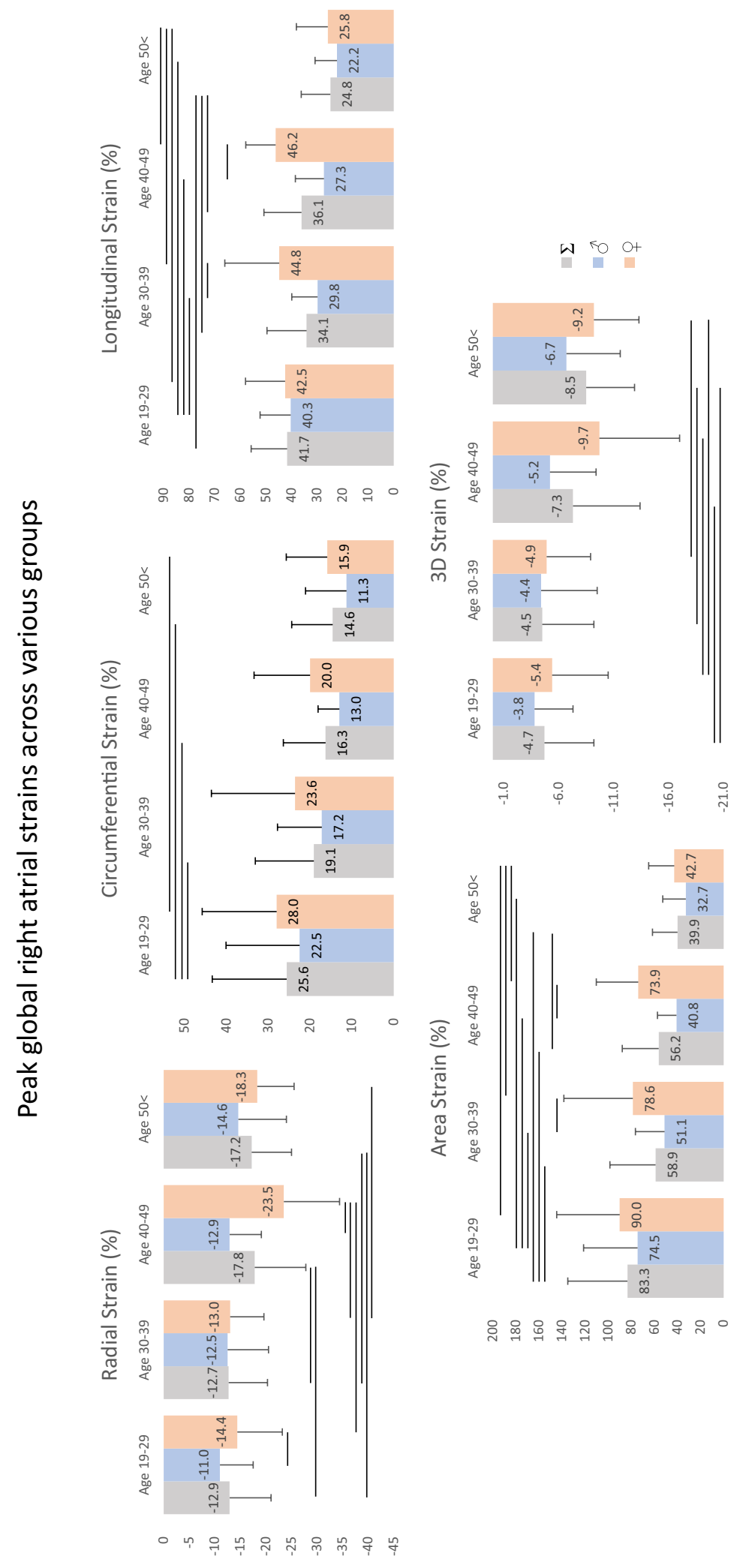

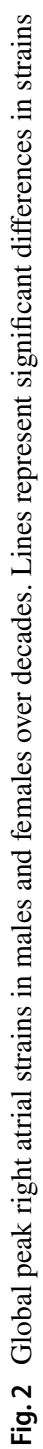


Table 2 Age-dependency of three-dimensional speckletracking echocardiographyderived peak mean segmental right atrial strain parameters and mean segmental right atrial strain parameters at atrial contraction

\begin{tabular}{lccccc}
\hline & All & $\begin{array}{l}\text { Aged } \\
19-29 \text { years } \\
(\mathrm{n}=103)\end{array}$ & $\begin{array}{l}\text { Aged } \\
30-39 \text { years } \\
(\mathrm{n}=42)\end{array}$ & $\begin{array}{l}\text { Aged } \\
40-49 \text { years } \\
(\mathrm{n}=15)\end{array}$ & $\begin{array}{l}\text { Aged } \\
\geq 50 \text { years } \\
(\mathrm{n}=25)\end{array}$ \\
\hline Peak mean segmental strains & & & & \\
RS (\%) & $-19.3 \pm 7.3$ & $-19.3 \pm 7.1$ & $-17.3 \pm 6.5$ & $-22.3 \pm 8.7$ & $-21.3 \pm 7.3$ \\
CS (\%) & $28.1 \pm 15.9$ & $32.0 \pm 17.3$ & $24.6 \pm 13.7$ & $24.1 \pm 11.6$ & $20.2 \pm 10.5$ \\
LS (\%) & $41.2 \pm 14.5$ & $45.5 \pm 13.3$ & $38.0 \pm 14.5$ & $40.9 \pm 15.3$ & $29.0 \pm 10.6^{* \dagger *}$ \\
3DS (\%) & $-11.5 \pm 5.4$ & $-11.2 \pm 5.4$ & $-10.0 \pm 4.8$ & $-13.7 \pm 6.2^{* \dagger}$ & $-13.8 \pm 4.9^{* \dagger}$ \\
AS (\%) & $78.7 \pm 47.8$ & $92.8 \pm 52.2$ & $66.5 \pm 38.8^{*}$ & $68.4 \pm 36.4$ & $47.8 \pm 21.8^{* \dagger *}$ \\
Mean segmental strains at atrial contraction & & & \\
RS (\%) & $-7.9 \pm 5.0$ & $-7.3 \pm 5.2$ & $-7.5 \pm 4.4$ & $-11.0 \pm 4.3^{*}$ & $-9.0 \pm 4.7$ \\
CS (\%) & $12.4 \pm 9.0$ & $12.8 \pm 9.9$ & $12.6 \pm 7.9$ & $12.8 \pm 8.9$ & $10.4 \pm 6.9$ \\
LS (\%) & $12.1 \pm 7.1$ & $12.9 \pm 7.7$ & $11.8 \pm 6.5$ & $12.3 \pm 6.1$ & $9.3 \pm 5.4^{*}$ \\
3DS (\%) & $-4.8 \pm 4.6$ & $-4.1 \pm 4.9$ & $-4.7 \pm 4.0$ & $-6.9 \pm 3.8^{*}$ & $-6.6 \pm 3.9^{* \dagger}$ \\
AS (\%) & $27.3 \pm 21.1$ & $30.2 \pm 23.9$ & $24.8 \pm 17.7$ & $27.6 \pm 19.1$ & $19.4 \pm 11.3^{*}$ \\
\hline
\end{tabular}

$* \mathrm{p}<0.05$ vs. patients aged $19-29$ years

$\dagger p<0.05$ vs. patients aged 39-39 years

${ }^{\ddagger} \mathrm{p}<0.05$ vs. patients aged $49-49$ years

Table 3 Age-dependency of three-dimensional speckle-tracking echocardiography-derived peak regional right atrial strain parameters

\begin{tabular}{|c|c|c|c|c|c|}
\hline & All & $\begin{array}{l}\text { Aged } \\
19-29 \text { years }\end{array}$ & $\begin{array}{l}\text { Aged } \\
30-39 \text { years }\end{array}$ & $\begin{array}{l}\text { Aged } \\
40-49 \text { years }\end{array}$ & $\begin{array}{l}\text { Aged } \\
\geq 50 \text { years }\end{array}$ \\
\hline $\mathrm{RS}_{\text {basal }}(\%)$ & $-15.4 \pm 7.6$ & $-13.9 \pm 7.0$ & $-14.9 \pm 7.1$ & $-20.6 \pm 9.5^{\dagger, \grave{\ddagger}}$ & $-19.0 \pm 7.0^{\dagger, \ddagger}$ \\
\hline $\mathrm{RS}_{\text {midatrial }}(\%)$ & $-19.3 \pm 8.5^{*}$ & $-19.5 \pm 8.7^{\dagger}$ & $-16.9 \pm 6.3$ & $-22.5 \pm 9.8^{\dagger *}$ & $-20.8 \pm 9.6^{\text {辛 }}$ \\
\hline $\mathrm{RS}_{\text {superior }}(\%)$ & $-25.3 \pm 14.2 *, * *$ & $-27.0 \pm 14.9^{\dagger, \dagger \dagger}$ & $-21.4 \pm 13.6^{\ddagger}$ & $-24.5 \pm 12.6$ & $-25.7 \pm 12.5^{\&}$ \\
\hline $\mathrm{CS}_{\text {basal }}(\%)$ & $26.6 \pm 12.3$ & $28.3 \pm 11.4$ & $23.7 \pm 12.1^{\dagger}$ & $30.7 \pm 14.6$ & $21.8 \pm 12.8^{\dagger, \#}$ \\
\hline $\mathrm{CS}_{\text {midatrial }}(\%)$ & $24.0 \pm 13.2$ & $27.4 \pm 14.1$ & $21.2 \pm 12.0^{\dagger \dagger}$ & $20.5 \pm 9.9^{\ddagger}$ & $17.0 \pm 8.3^{\dagger \dagger}$ \\
\hline $\mathrm{CS}_{\text {superior }}(\%)$ & $36.3 \pm 35.1 *, * *$ & $44.6 \pm 40.7^{\dagger, \dagger \dagger}$ & $30.9 \pm 25.5^{+\$,+\dagger \dagger}$ & $19.3 \pm 18.0^{\dagger \dagger \dagger}$ & $21.9 \pm 20.5^{\dagger \dagger \dagger}$ \\
\hline $\mathrm{LS}_{\text {basal }}(\%)$ & $44.9 \pm 20.3$ & $50.0 \pm 18.7$ & $40.0 \pm 17.6^{\dagger}$ & $48.8 \pm 26.1$ & 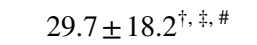 \\
\hline $\mathrm{LS}_{\text {midatrial }}(\%)$ & $46.5 \pm 18.5$ & $49.4 \pm 18.3$ & $45.1 \pm 20.1$ & $48.5 \pm 16.2$ & 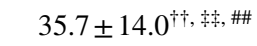 \\
\hline $\mathrm{LS}_{\text {superior }}(\%)$ & $27.6 \pm 21.6^{*}, * *$ & $32.8 \pm 25.0^{\dagger, \dagger \dagger}$ & $24.4 \pm 15.7^{\ddagger},+, \dagger \dagger \dagger$ & $17.7 \pm 13.9^{\ddagger}$ & $17.9 \pm 10.1^{\dagger \dagger \dagger, \&, \& \&}$ \\
\hline $3 \mathrm{DS}_{\text {basal }}(\%)$ & $-8.7 \pm 5.5$ & $-7.4 \pm 4.7$ & $-8.8 \pm 5.4$ & $-11.7 \pm 6.3^{\dagger}$ & $-12.5 \pm 6.4^{\dagger, \ddagger}$ \\
\hline $3 \mathrm{DS}_{\text {midatrial }}(\%)$ & $-10.4 \pm 5.6^{*}$ & $-10.3 \pm 5.9^{\dagger}$ & $-8.9 \pm 4.1$ & $-11.9 \pm 6.4^{\ddagger}$ & $-12.3 \pm 5.8^{\dagger}$ \\
\hline $3 \mathrm{DS}_{\text {superior }}(\%)$ & $-17.5 \pm 11.5 *, * *$ & $-18.6 \pm 12.1^{\dagger, \dagger \dagger}$ & $-13.7 \pm 10.5^{\ddagger}$, & $-19.4 \pm 11.2^{\ddagger}$ & $-18.2 \pm 9.9^{\&, \& \&}$ \\
\hline $\mathrm{AS}_{\text {basal }}(\%)$ & $68.6 \pm 35.1$ & $77.8 \pm 31.1$ & $58.4 \pm 31.9^{\dagger}$ & $79.9 \pm 50.1$ & $41.3 \pm 26.7^{\dagger, \grave{+}, \#}$ \\
\hline $\mathrm{AS}_{\text {midatrial }}(\%)$ & $79.9 \pm 40.8^{*}$ & $90.0 \pm 41.0^{\dagger}$ & $72.9 \pm 44.0^{\dagger \dagger}$ & $74.1 \pm 29.9$ & $53.7 \pm 22.6^{\dagger \dagger}$ \\
\hline $\mathrm{AS}_{\text {superior }}(\%)$ & $92.2 \pm 118.6^{*}$ & $119.7 \pm 145.7^{\dagger, \dagger \dagger}$ & $69.1 \pm 63.9^{\dagger \dagger \dagger}$ & $42.5 \pm 49.5^{\ddagger}$ & $48.9 \pm 44.3^{\dagger \dagger \dagger}$ \\
\hline
\end{tabular}

$* \mathrm{p}<0.05$ vs. patients with same strain basal all

$* * \mathrm{p}<0.05$ vs. patients with same strain midatrial all

$\dagger \mathrm{p}<0.05$ vs. patients with same strain basal aged 19-29 years

${ }^{\dagger} \mathrm{p}<0.05$ vs. patients with same strain midatrial aged 19-29 years

${ }^{\dagger \dagger} \mathrm{p}<0.05$ vs. patients with same strain superior aged 19-29 years

$\$ \mathrm{p}<0.05$ vs. patients with same strain basal aged 30-39 years

$\$ \mathrm{p}<0.05$ vs. patients with same strain midatrial aged 30-39 years

$\$ p<0.05$ vs. patients with same strain superior aged 30-39 years

\# $\mathrm{p}<0.05$ vs. patients with same strain basal aged $40-49$ years

${ }^{\# \#} \mathrm{p}<0.05$ vs. patients with same strain midatrial aged $40-49$ years

${ }^{\&} \mathrm{p}<0.05$ vs. patients with same strain basal aged $>50$ years

${ }^{\& \&} \mathrm{p}<0.05$ vs. patients with same strain basal aged $>50$ years 


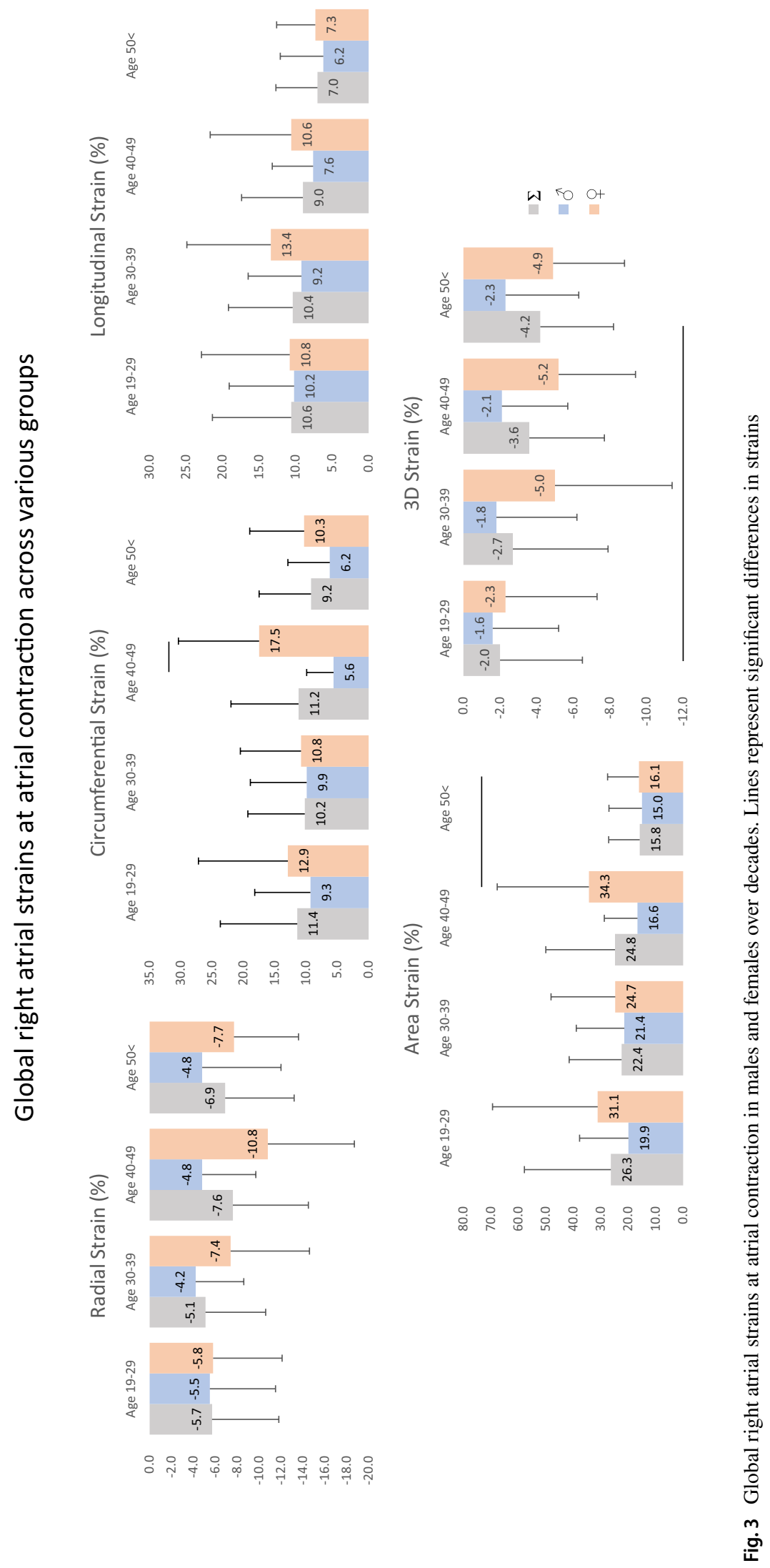


Peak global right atrial strains

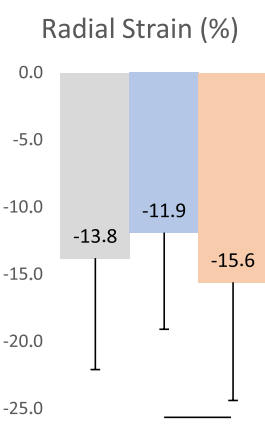

$-30.0$

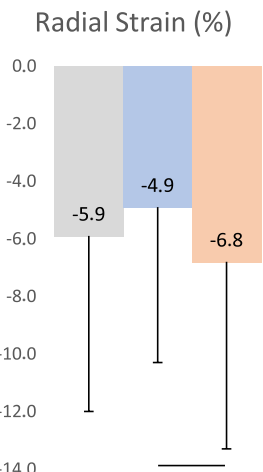

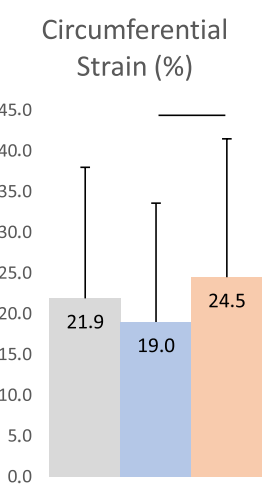
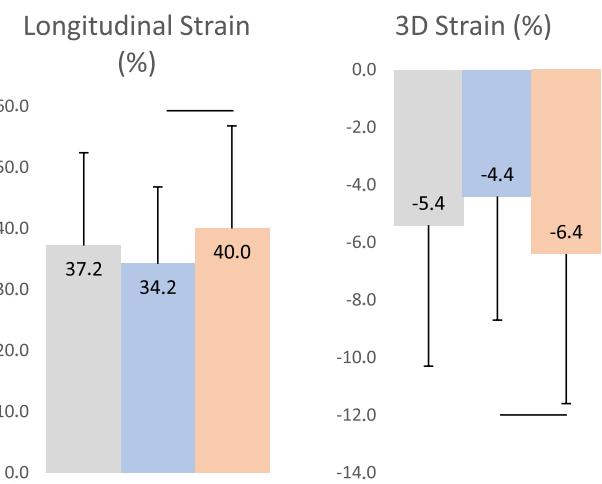

Global right atrial strains at atrial contraction
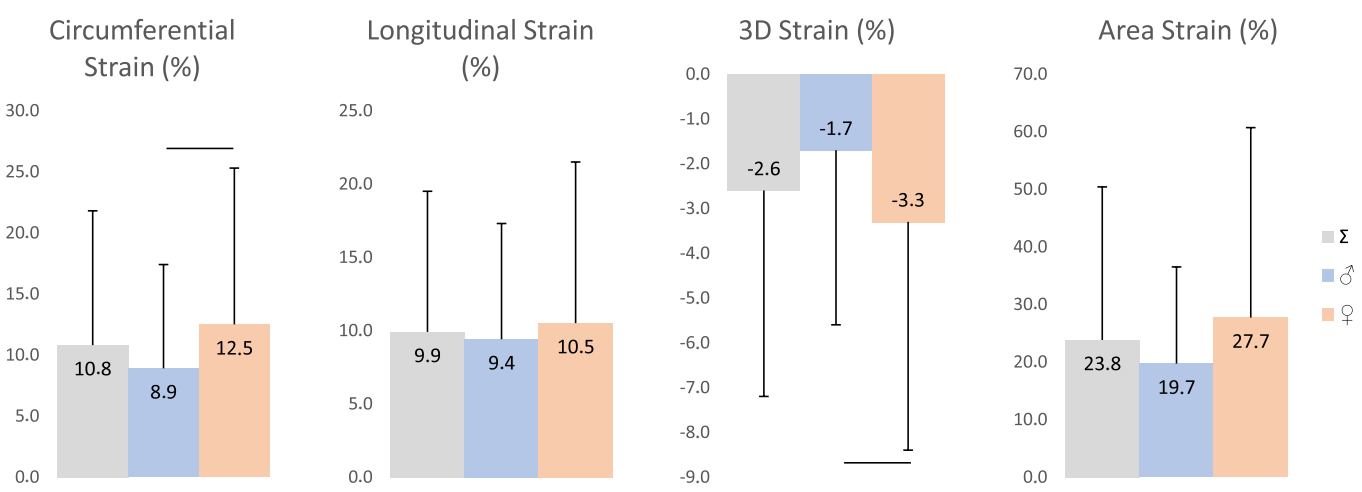

Fig. 4 Gender dependency of global peak right atrial strains and global right atrial strains at atrial contraction. Lines represent significant difference in strains between genders

With the present study normal reference values of 3DSTE-derived RA strains have been determined. Specific pattern of changes of different RA strains could be demonstrated over decades with gender differences. The present study could also highlight our attention on the dissimilarities between normal function of the LA and RA in healthy individuals as suggested in an earlier 2DSTE study by Moustafa et al. [15]. In a recent study from our MAGYAR-Healthy Study normal reference values of LA strains have been demonstrated, which showed different behaviour of LA strains as compared to RA strains [16]. RA strains show obvious gender-dependency which could not be confirmed in LA strains. Further studies are warranted to confirm our findings in a larger population and also to further assess RA strains in different pathological states [4-8].

\section{Limitation section}

The following most important limitations should be considered when interpreting the results:
- One of the most important limitation of the study is related to the technical limitation of 3DSTE due to its limited spatial and temporal resolution. It means that average image quality during 3DSTE is worse compared to the corresponding routine $2 \mathrm{D}$ echocardiographic image.

- There is a debate whether the atrial septum is part of which atria. In the present study, a 3D virtual RA model was used for assessments including the atrial septum.

- Assessment of atrial strains are only validated against 2D echocardiography [17], 2DSTE [18] and volumetric real-time 3D echocardiography [19].

- Only normal reference values of RA strains were assessed, it was not aimed to determine these values in case of other heart chambers or to measure the volumetric properties of the RA. Strain rate parameters were also not calculated.

- As mentioned in the methods section, twin-peak RA strain curves were analysed featuring RA reservoir (first peak) and atrial booster (second peak) function. Normal reference values for strains characterizing conduit function were not calculated in this study. 
Table 4 Age-dependency of three-dimensional speckletracking echocardiographyderived regional right atrial strain parameters at atrial contraction

\begin{tabular}{|c|c|c|c|c|c|}
\hline & All & $\begin{array}{l}\text { Aged } \\
19-29 \text { years }\end{array}$ & $\begin{array}{l}\text { Aged } \\
30-39 \text { years }\end{array}$ & $\begin{array}{l}\text { Aged } \\
40-49 \text { years }\end{array}$ & $\begin{array}{l}\text { Aged } \\
\geq 50 \text { years }\end{array}$ \\
\hline $\mathrm{RS}_{\text {basal }}(\%)$ & $-6.3 \pm 5.8$ & $-4.5 \pm 4.9$ & $-7.3 \pm 6.3^{\dagger}$ & $-11.4 \pm 5.5^{\dagger, \ddagger}$ & $-9.0 \pm 5.7^{\dagger}$ \\
\hline $\mathrm{RS}_{\text {midatrial }}(\%)$ & $-7.9 \pm 5.4^{*}$ & $-7.7 \pm 5.7^{\dagger}$ & $-7.4 \pm 4.8$ & $-11.0 \pm 5.4^{\dagger \dagger}$, 蛙 & $-8.1 \pm 4.8$ \\
\hline $\mathrm{RS}_{\text {superior }}(\%)$ & $-10.1 \pm 8.6^{*, * *}$ & $-10.7 \pm 9.8^{\dagger, \dagger \dagger}$ & $-8.2 \pm 6.2$ & $-10.3 \pm 7.7$ & $-10.4 \pm 7.1$ \\
\hline $\mathrm{CS}_{\text {basal }}(\%)$ & $10.7 \pm 7.2$ & $9.6 \pm 6.6$ & $11.5 \pm 7.4$ & $14.3 \pm 7.8^{\dagger}$ & $11.7 \pm 8.4$ \\
\hline $\mathrm{CS}_{\text {midatrial }}(\%)$ & $10.3 \pm 7.4$ & $10.1 \pm 7.6$ & $10.9 \pm 7.3$ & $9.4 \pm 8.2$ & $10.5 \pm 6.8$ \\
\hline $\mathrm{CS}_{\text {superior }}(\%)$ & $18.0 \pm 20.9^{*}, * *$ & $21.7 \pm 24.4^{\dagger, \dagger}$ & $17.0 \pm 16.1^{\ddagger}$, & $11.2 \pm 12.6$ & $8.7 \pm 9.9^{\dagger \dagger, t \dagger}$ \\
\hline $\mathrm{LS}_{\text {basal }}(\%)$ & $11.3 \pm 7.8$ & $12.4 \pm 8.2$ & $9.5 \pm 7.1^{\dagger}$ & $13.2 \pm 7.4$ & $9.1 \pm 6.7$ \\
\hline $\mathrm{LS}_{\text {midatrial }}(\%)$ & $12.5 \pm 8.2$ & $12.8 \pm 8.9$ & $12.9 \pm 7.8$ & $12.4 \pm 6.2$ & $10.9 \pm 7.0$ \\
\hline $\mathrm{LS}_{\text {superior }}(\%)$ & $12.5 \pm 13.3$ & $13.9 \pm 15.6$ & $12.6 \pm 9.3$ & $10.8 \pm 12.7$ & $7.2 \pm 6.6^{\dagger \dagger \dagger}$ \\
\hline $3 \mathrm{DS}_{\text {basal }}(\%)$ & $-3.1 \pm 5.3$ & $-1.5 \pm 4.7$ & $-4.0 \pm 5.3^{\dagger}$ & $-6.0 \pm 5.7 \dagger$ & $-6.1 \pm 5.0^{\dagger}$ \\
\hline $3 \mathrm{DS}_{\text {midatrial }}(\%)$ & $-4.5 \pm 4.8^{*}$ & $-4.1 \pm 5.1^{\dagger}$ & $-4.1 \pm 4.3$ & $-6.4 \pm 3.9$ & $-5.9 \pm 4.1$ \\
\hline $3 \mathrm{DS}_{\text {superior }}(\%)$ & $-7.8 \pm 8.1^{*}, * *$ & $-8.0 \pm 9.1^{\dagger, \dagger \dagger}$ & $-6.8 \pm 6.3^{\ddagger}$ & $-8.7 \pm 7.3$ & $-8.2 \pm 7.2$ \\
\hline $\mathrm{AS}_{\text {basal }}(\%)$ & $22.0 \pm 14.4$ & $23.0 \pm 14.6$ & $19.5 \pm 14.9$ & $28.3 \pm 15.0$ & $18.3 \pm 11.1^{\#}$ \\
\hline $\mathrm{AS}_{\text {midatrial }}(\%)$ & $24.8 \pm 17.5$ & $25.6 \pm 18.7$ & $24.3 \pm 16.8$ & $27.0 \pm 18.0$ & $21.5 \pm 13.0$ \\
\hline $\mathrm{AS}_{\text {superior }}(\%)$ & $38.9 \pm 54.3^{*}, * *$ & $48.0 \pm 66.4^{\dagger, \dagger \dagger}$ & $33.6 \pm 32.5^{\ddagger}$ & $27.4 \pm 36.8$ & $18.0 \pm 19.4^{\dagger \dagger,+1+\infty}$ \\
\hline
\end{tabular}

$* \mathrm{p}<0.05$ vs. patients with same strain basal all

$* * \mathrm{p}<0.05$ vs. patients with same strain midatrial all

${ }^{\dagger} \mathrm{p}<0.05$ vs. patients with same strain basal aged 19-29 years

${ }^{\dagger \dagger} \mathrm{p}<0.05$ vs. patients with same strain midatrial aged 19-29 years

${ }^{\dagger \dagger} \mathrm{p}<0.05$ vs. patients with same strain superior aged 19-29 years

${ }^{\ddagger} \mathrm{p}<0.05$ vs. patients with same strain basal aged 30-39 years

${ }_{*} \mathrm{p}<0.05$ vs. patients with same strain midatrial aged $30-39$ years

$\$ \mathrm{p}<0.05$ vs. patients with same strain midatrial aged 30-39 years

${ }^{\#} \mathrm{p}<0.05$ vs. patients with same strain basal aged $40-49$ years
- RA highly depends on morphological and functional properties of RV (and pulmonary artery). However, data of all subjects were in normal ranges and had no cardiac or pulmonary diseases or other factors that could affect the results.

- LV segmentation model was used during RA assessments.

\section{Conclusion}

3DSTE-derived RA normal reference values with age-, gender-dependency and regional values are demonstrated in a healthy adult population.

Acknowledgements Open access funding provided by University of Szeged (SZTE).

\section{Compliance with ethical standards}

Conflict of interest Attila Nemes declares that he has no conflict of interest. Árpád Kormányos declares that he has no conflict of interest. Péter Domsik declares that he has no conflict of interest. Anita Kalapos declares that she has no conflict of interest. Csaba Lengyel declares that he has no conflict of interest. Tamás Forster declares that he has no conflict of interest.

Ethical approval All procedures performed in studies involving human participants were in accordance with the ethical standards of the institutional and/or national research committee and with the 1964 Helsinki declaration and its later amendments or comparable ethical standards.

Informed consent Informed consent was obtained from all individual participants included in the study.

Open Access This article is distributed under the terms of the Creative Commons Attribution 4.0 International License (http://creativeco mmons.org/licenses/by/4.0/), which permits unrestricted use, distribution, and reproduction in any medium, provided you give appropriate credit to the original author(s) and the source, provide a link to the Creative Commons license, and indicate if changes were made.

\section{References}

1. Malenfant S, Neyron AS, Paulin R, Potus F, Meloche J, Provencher S, Bonnet S (2013) Signal transduction in the development of pulmonary arterial hypertension. Pulm Circ 3:278-293

2. Nemes A, Forster T (2016) Echocardiographic evaluation of the right atrium-from M-mode to 3D speckle-tracking imaging. Orv Hetil 157:1698-1707 
3. Nemes A, Kalapos A, Domsik P, Forster T (2012) Threedimensional speckle-tracking echocardiography-a further step in non-invasive three-dimensional cardiac imaging. Orv Hetil 153:1570-1577

4. Nemes A, Havasi K, Domsik P, Kalapos A, Forster T (2015) Evaluation of right atrial dysfunction in patients with corrected tetralogy of Fallot using 3D speckle-tracking echocardiography Insights from the CSONGRAD Registry and MAGYAR-Path Study. Herz 40:980-988

5. Nemes A, Domsik P, Kalapos A, Gavallér H, Oszlánczi M, Forster T (2016) Right atrial deformation analysis in isolated left ventricular noncompaction-insights from the three-dimensional speckle tracking echocardiographic MAGYAR-Path Study. Rev Port Cardiol 35:515-521

6. Nemes A, Marton I, Domsik P, Kalapos A, Pósfai É, Modok S, Kormányos Á, Ambrus N, Borbényi Z, Forster T (2017) The right atrium in idiopathic hypereosinophilic syndrome: insights from the 3D speckle tracking echocardiographic MAGYAR-Path Study. Herz. https://doi.org/10.1007/s00059-017-4652-4

7. Nemes A, Földeák D, Domsik P, Kalapos A, Kormányos Á, Borbényi Z, Forster T (2018) Right atrial deformation analysis in cardiac amyloidosis-results from the three-dimensional speckletracking echocardiographic MAGYAR-Path Study. Arq Bras Cardiol 111:384-391

8. Nemes A, Domsik P, Kalapos A, Kormányos Á, Ambrus N, Forster T (2018) Three-dimensional speckle-tracking echocardiography detects different patterns of right atrial dysfunction in selected disorders: a short summary from the MAGYAR-Path study. Quant Imaging Med Surg 8:182-186

9. Sakata K, Uesugi Y, Isaka A, Minamishima T, Matsushita K, Satoh T, Yoshino Y (2016) Evaluation of right atrial function using right atrial speckle tracking analysis in patients with pulmonary artery hypertension. J Echocardiogr 14:30-38

10. Khedr L, Elasfar A, Hekal S, ElGendy E, Abdulaal M, Elsokkary $\mathrm{H}$, Ashmawy M (2018) Assessment of left and right atrial geometrical changes in patients with stable coronary artery disease: left and right atrial strain and strain rate imaging study. Egypt Heart J 70:101-106

11. Ojaghi Haghighi Z, Naderi N, Amin A, Taghavi S, Sadeghi M, Moladoust H, Maleki M, Ojaghi Haghighi H (2011) Quantitative assessment of right atrial function by strain and strain rate imaging in patients with heart failure. Acta Cardiol 66:737-742

12. D’Ascenzi F, Cameli M, Padeletti M, Lisi M, Zacà V, Natali B, Malandrino A, Alvino F, Morelli M, Vassallo GM, Meniconi C,
Bonifazi M, Causarano A, Mondillo S (2013) Characterization of right atrial function and dimension in top-level athletes: a speckle tracking study. Int J Cardiovasc Imaging 29:87-94

13. Padeletti M, Cameli M, Lisi M, Malandrino A, Zacà V, Mondillo S (2012) Reference values of right atrial longitudinal strain imaging by two-dimensional speckle tracking. Echocardiography 29:147-152

14. Safir-Mardanloo A, Khorsand Askari M, Lotfi Tokaldany M, Ashrafi MM, Sadeghian H (2019) Normal values for tissue velocity and strain rate imaging parameters of left and right atrial myocardium in normal subjects. Echocardiography 36:521-527

15. Moustafa S, Zuhairy H, Youssef MA, Alvarez N, Connelly MS, Prieur T, Mookadam F (2015) Right and left atrial dissimilarities in normal subjects explored by speckle tracking echocardiography. Echocardiography 32:1392-1399

16. Nemes A, Kormányos Á, Domsik P, Kalapos A, Lengyel C, Forster T (2019) Normal reference values of three-dimensional speckle-tracking echocardiography-derived left atrial strain parameters (results from the MAGYAR-Healthy Study). Int J Cardiovasc Imaging 35:991-998

17. Nemes A, Domsik P, Kalapos A, Lengyel C, Orosz A, Forster $\mathrm{T}$ (2014) Comparison of three-dimensional speckle tracking echocardiography and two-dimensional echocardiography for evaluation of left atrial size and function in healthy volunteers (results from the MAGYAR-Healthy Study). Echocardiography 31:865-871

18. Mochizuki A, Yuda S, Oi Y, Kawamukai M, Nishida J, Kouzu H, Muranaka A, Kokubu N, Shimoshige S, Hashimoto A, Tsuchihashi K, Watanabe N, Miura T (2013) Assessment of left atrial deformation and synchrony by three-dimensional speckle-tracking echocardiography: comparative studies in healthy subjects and patients with atrial fibrillation. J Am Soc Echocardiogr $26: 165-174$

19. Kleijn SA, Aly MF, Terwee CB, van Rossum AC, Kamp O (2011) Comparison between direct volumetric and speckle tracking methodologies for left ventricular and left atrial chamber quantification by three-dimensional echocardiography. Am J Cardiol 108:1038-1044

Publisher's Note Springer Nature remains neutral with regard to jurisdictional claims in published maps and institutional affiliations. 